\title{
Review \\ Current Situation of Proton Therapy for Hodgkin Lymphoma: From Expectations to Evidence
}

\author{
Pierre Loap ${ }^{1,2, *}$, Alfredo Mirandola ${ }^{2}$, Ludovic De Marzi ${ }^{1,3} \mathbb{D}$, Remi Dendale ${ }^{1}$, Alberto Iannalfi ${ }^{2}$, Viviana Vitolo ${ }^{2}$, \\ Amelia Barcellini ${ }^{2}$ (D), Andrea Riccardo Filippi 4 (D), Barbara Alicja Jereczek-Fossa ${ }^{5,6}$, Youlia Kirova ${ }^{1,+}$ \\ and Ester Orlandi ${ }^{2,+}$
}

\section{check for} updates

Citation: Loap, P.; Mirandola, A.; De Marzi, L.; Dendale, R.; Iannalfi, A.; Vitolo, V.; Barcellini, A.; Filippi, A.R.; Jereczek-Fossa, B.A.; Kirova, Y.; et al. Current Situation of Proton Therapy for Hodgkin Lymphoma: From Expectations to Evidence. Cancers 2021, 13, 3746. https://doi.org/ 10.3390/cancers13153746

Academic Editors: Laura Cella, Giuseppe Palma and Andrew Hope

Received: 28 June 2021

Accepted: 23 July 2021

Published: 26 July 2021

Publisher's Note: MDPI stays neutral with regard to jurisdictional claims in published maps and institutional affiliations.

Copyright: (c) 2021 by the authors. Licensee MDPI, Basel, Switzerland. This article is an open access article distributed under the terms and conditions of the Creative Commons Attribution (CC BY) license (https:// creativecommons.org/licenses/by/ $4.0 /)$.
1 Department of Radiation Oncology, Institut Curie, 75005 Paris, France; ludovic.demarzi@curie.fr (L.D.M.); remi.dendale@curie.fr (R.D.); Youlia.kirova@curie.fr (Y.K.)

2 Radiation Oncology Clinical Department, National Center for Oncological Hadrontherapy (CNAO), 27100 Pavia, Italy; Alfredo.Mirandola@cnao.it (A.M.); alberto.iannalfi@cnao.it (A.I.); viviana.vitolo@cnao.it (V.V.); amelia.barcellini@cnao.it (A.B.); ester.orlandi@cnao.it (E.O.)

3 Institut Curie, PSL Research University, University Paris Saclay, INSERM LITO, 91400 Orsay, France

4 Radiation Oncology Department, Fondazione IRCCS Policlinico San Matteo and University of Pavia, 27100 Pavia, Italy; a.filippi@smatteo.pv.it

5 Department of Oncology and Hemato-Oncology, University of Milan, 20122 Milan, Italy; barbara.jereczek@ieo.it

6 Division of Radiotherapy, IEO European Institute of Oncology IRCCS, 20141 Milan, Italy

* Correspondence: pierre.loap@gmail.com

$\dagger$ These authors contributed equally to this paper as senior co-last authors.

Simple Summary: Hodgkin lymphoma (HL) is a highly curable disease; in this context, the limitation of late adverse events is of prime importance for the patient. Proton therapy for mediastinal HL irradiation theoretically limits secondary cancer excess risk and should reduce late toxicities compared with classical radiation therapy techniques. However, due to the limited clinical experience, strong evidence is still lacking to support proton therapy in HL management despite excellent tolerance. In addition, randomized controlled trials are probably unrealistic in this context. National and international registries may be useful to strengthen support for HL proton therapy.

Abstract: Consolidative radiation therapy (RT) is of prime importance for early-stage Hodgkin lymphoma (HL) management since it significantly increases progression-free survival (PFS). Nevertheless, first-generation techniques, relying on large irradiation fields, delivered significant radiation doses to critical organs-at-risk (OARs, such as the heart, to the lung or the breasts) when treating mediastinal HL; consequently, secondary cancers, and cardiac and lung toxicity were substantially increased. Fortunately, HL RT has drastically evolved and, nowadays, state-of-the-art RT techniques efficiently spare critical organs-at-risks without altering local control or overall survival. Recently, proton therapy has been evaluated for mediastinal HL treatment, due to its possibility to significantly reduce integral dose to OARs, which is expected to limit second neoplasm risk and reduce late toxicity. Nevertheless, clinical experience for this recent technique is still limited worldwide. Based on current literature, this critical review aims to examine the current practice of proton therapy for mediastinal HL irradiation.

Keywords: hodgkin lymphoma; proton therapy; NTCP model; toxicity

\section{Introduction}

Hodgkin lymphoma (HL) is a rare hematologic malignancy with an estimated incidence of 2.7-2.8 cases per 100,000 person-year [1] and is characterized by a high curative rate, evaluated between $80 \%$ and $90 \%$ [2]. For favorable and unfavorable early-stage HL, consolidative radiation therapy (RT) is currently considered as a gold standard since it significantly improves progression-free survival [3]. More controversially, RT can also 
be considered for some advanced-stage HL, as well as in the context of relapsed or refractory HL. Unfortunately, first generation radiation techniques that heavily relied on two-dimensional planning and large extended fields were associated with a significantly increased morbidity for mediastinal HL irradiation, notably including secondary cancers, and cardiac and pulmonary toxicity [4]. Treatment planning evolutions were subsequently achieved and, nowadays, widespread use of smaller target volumes limited to the initially involved sites or to the involved nodes allowed a substantial reduction of integral dose delivered to the patient [5]. Additionally, drastic technical progress was made to spare organs-at-risks (OAR) without altering local tumor control or patient survival. Such evolutions included generalization of intensity-modulated radiation therapy (IMRT) and democratization of respiratory control such as gating or deep-inspiration breath-hold (DIBH) [6]. The issue around radiation-related toxicity after HL treatment has significantly evolved over the years. Proton therapy has recently been proposed to further reduce late toxicity in the context of mediastinal HL irradiation. Proton beams deliver most of their energy at the end of their ranges, translating into a limited distant-to-target dose deposition compared with IMRT. For mediastinal HL, proton therapy has thus demonstrated a major dosimetric benefit for cardiac sparing [7] while decreasing the integral dose to the lungs and to the breasts. In addition, newer IMRT techniques for HL management, such as volumetric modulated arctherapy (VMAT) or helical tomotherapy sensibly increase low-dose exposure to OARs which had been debatably suspected to potentially increase secondary malignancies, based on low-dose radiation data from A bomb survivors [8]; however, other biological models failed to demonstrate any risk increase of second cancers for low-dose exposure [9] and this issue is still controversial. Consequently, proton therapy might be an excellent therapeutic option for selected mediastinal HL patients who would benefit from reduced radiation exposure to the OARs; such patients could correspond to those with significant baseline cardiac risk factors or young female patients. However, while expectations around HL proton therapy for late toxicity reduction are high, clinical experience is still limited. The purpose of this review is to provide a contextualized analysis of the expectations and of the current clinical evidence for mediastinal HL management with proton therapy.

\section{Modeling the Benefit of Proton Therapy for Hodgkin Lymphoma Irradiation}

Due to their physical properties, proton beams release most of the energy towards the end on their range, a phenomenon known as the "Bragg peak", which allows to substantially reduce distant-to-target dose deposition compared with classic photon radiation therapy techniques. Consequently, the theoretical benefit of proton therapy for HL irradiation is based on the substantial OAR sparing compared with modern photon radiation therapy techniques. Figure 1 provides a typical example of significant OAR sparing with proton therapy compared with VMAT. The plan comparison was done with optimized multi-arc VMAT technique with the same dose constraints.

\subsection{Reduction of Secondary Neoplasms}

Hodgkin lymphoma (HL) survivors have a significantly increased risk of secondary neoplasms, which may result from both chemotherapy regimens and radiotherapy. Based on a cohort of $3905 \mathrm{HL}$ patients with a median follow-up of 19.1 years, Schaapveld et al. [10] estimated that the standardized incidence ratio (SIR) of secondary cancers was 4.6. The risk was particularly increased for non-Hodgkin lymphomas $(\mathrm{SIR}=13.4)$, thyroid cancers $(\mathrm{SIR}=14.0)$ and mesothelioma (SIR = 15.1); however, the greatest epidemiological burden corresponded to breast cancers, with an excess absolute risk (EAR) of 54.3 cases for 10,000 person-years, and to lung cancers with an EAR of 24.6 cases for 10,000 person-years. The benefit of HL proton therapy for secondary neoplasm risk reduction was expected based on the principle that lower doses were associated with a reduced risk of radiationinduced cancer [11]. This concept of a linear no-threshold model has been proposed by retrospective analyses of second cancer incidence in A-bomb survivors in Japan; on this 
basis, mathematical models predicting radiation-induced secondary cancers were proposed by Schneider et al. (a mechanistic model using the linear quadratic formula) [12] or Sachs \& Brenner (a biological-based initiation-inactivation-proliferation model) [13].

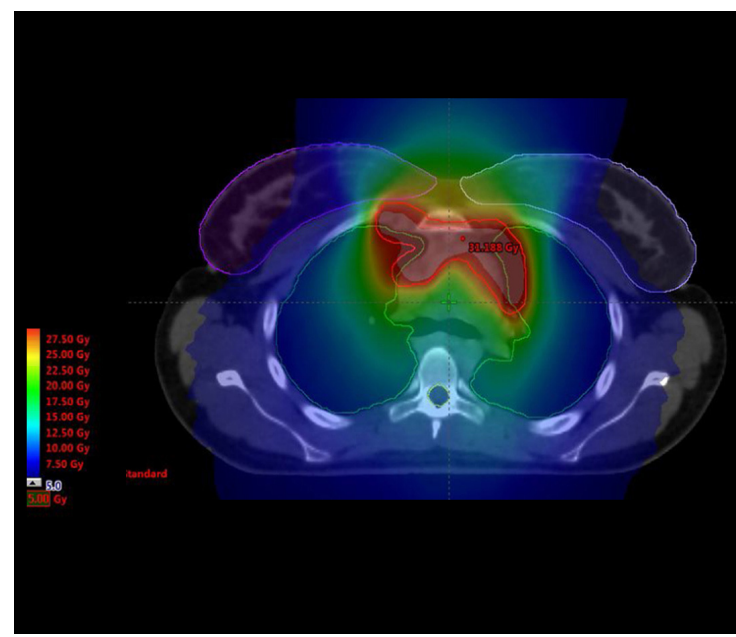

(a)

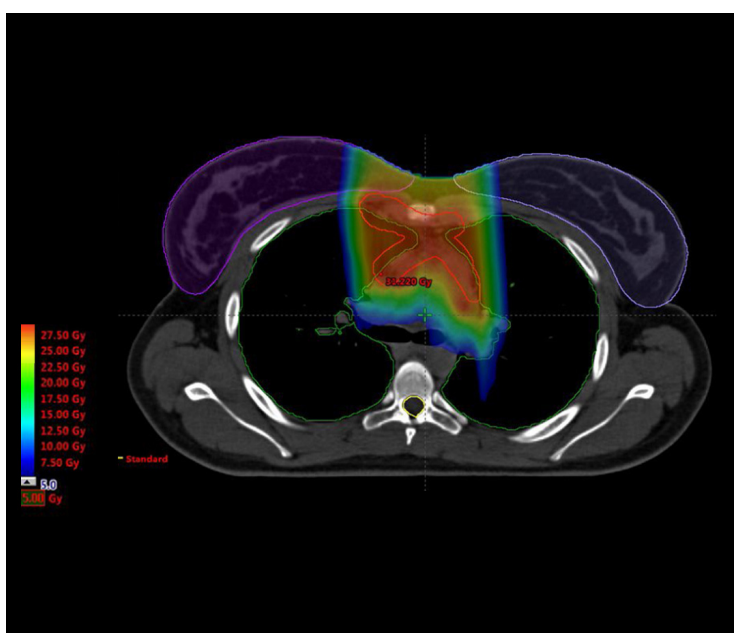

(b)

Figure 1. Example of organ-at-risk (OAR) sparing with proton therapy for Hodgkin lymphoma. This 24-year-old patient had to be treated to the dose of 30.6 Gy to the PTV (red), partly localized in the inferior anterior mediastinum, under the origin of the left main coronary artery. A comparative dosimetry was realized between DIBH-VMAT plan (a) and proton therapy (b). Proton therapy reduced radiation exposure to the breasts (delineated in purple), to the lungs (delineated in green), to the heart and to the esophagus, compared with VMAT; this may translate into fewer OAR late toxicities (and potentially fewer secondary cancers). In particular, the mean heart dose was reduced from 3.7 Gy with VMAT to 2.6 Gy with proton therapy, which might reduce late radiation-induced cardiotoxicity. This patient was finally treated using DIBH involved site proton therapy.

Based on the Schneider model and taking as a reference the anterior-posterior threedimensional (3D) RT (3D-RT) planning, Cella et al. [14] found that HL proton therapy was associated with a significantly reduced relative risk (RR) of secondary breast cancers $(\mathrm{RR}=0.3-0.7)$ compared with 3D-RT; while a benefit for secondary lung cancers was also observed $(R R=0.6-0.7)$, this was not the case for thyroid cancers. Taking the "butterfly" IMRT technique [15] as a reference, König et al. [16] similarly demonstrated that secondary breast, lung, and esophageal cancers could be reduced by $56.4 \%, 54.4 \%$ and $24.4 \%$ respectively. Scorsetti et al. [17] evidenced that proton therapy could also reduce thyroid cancers compared with VMAT; however, this benefit is expected to be limited to an EAR reduction of 0.2 for 10,000 person-years. However, modern RT techniques currently used for HL irradiation ("butterfly" IMRT, VMAT or tomotherapy) may be associated with an increased low-dose bath compared with 3D-RT [8], which usually results from a compromise between heart and breast sparing, but which might be associated with uncertainties regarding secondary malignancy risk. Timlin et al. [18] estimated that the overall cumulated risk of secondary cancers after HL RT (including breast, esophagus, heart, liver, lung, pharyngeal, spinal cord, stomach, thyroid, bone, and soft tissues malignancies) would be significantly lowered with proton therapy compared with IMRT or VMAT (reduction of EAR of $40 \%$ and $28 \%$ respectively) but would be somewhat similar compared with 3D-RT (EAR reduction of $4 \%$ ). However, it should be stressed that when applying strict dose constraints to the breast [19], risk of secondary breast cancer is similar between 3D-RT and VMAT [20]. Consequently, a comparison between 3D-RT, optimized multi-arc VMAT and proton therapy using strictly similar dose constraints to the breasts might be considered in the future to precise these uncertainties. 


\subsection{Reduction of Radiation-Induced Cardiotoxicity}

Cardiotoxicity is another major concern for HL survivors. Van Nilwegen et al. [21] estimated on a cohort of 2524 patients with a median follow-up of 20 years that these patients had a 4-6-fold increase of heart failure (HF) or congestive heart failure (CHF). The cumulative incidences of CHD, HF, and valvular heart disease (VHD) were $20 \%, 11 \%$ and $31 \%$ respectively. Mediastinal RT was found to increase $\mathrm{CHD}$ with a hazard ratio (HR) of 2.7, VHD with a HR of 6.6 and HF with a RR of 2.7. Significant interactions were found with anthracyclines-based chemotherapy use and smoking status.

Long-term follow-up of patients treated with RT for diverse types of cancer allowed the development of normal tissue complication probability (NTCP) models to estimate the risk of radiation-induced side effects. In particular, these models could be used to estimate radiation-induced cardiotoxicity risk: Gagliardi et al. summarized available cardiac NTCP models [22] which focused on cardiac mortality (based on a breast and an HL cohort), pericarditis (based on historical combined data and an esophagus cancer cohort) and cardiac perfusion defects (based on an HL cohort). In addition, an NTCP model for VHD risk estimation has been developed with an HL cohort, based on lung and heart dosimetric parameters [23]. However, none of these cardiac NTCP models consider cardiac substructures. Yet, Hoppe et al. [24] demonstrated that, for HL proton therapy, gross heart dosimetric parameters, such as mean heart dose (MHD), were not representative of radiation exposure to potentially critical cardiac substructures: correlation coefficients between MHD and cardiac substructures were weak for intensity-modulated proton therapy (IMPT); for instance, $r=0.5$ for the tricuspid valve and $r=0.52$ for the mitral valve. In this respect, current NTCP cardiotoxicity models, which are all developed with photon-based RT techniques, could be misleading when applied to proton therapy. Nevertheless, dosimetric comparison between HL proton therapy and photon techniques (3D or IMRT) demonstrated a significant gain on all cardiac substructures (cardiac cavities, valves, and coronary arteries) [7], and Taparra et al. [25] found that the superiority of IMPT over IMRT at the substructure level was conserved even with ECG-gated cardiac substructure sparing (CSS) planning. An example of comparative dosimetry between IMPT and IMRT is provided in Figure 1.

However, this apparent dosimetric superiority of proton therapy over photon techniques does not necessarily translate into clinical benefits, according to current NTCP models. Toltz et al. [26] did not find any significant reduction of cardiac mortality between free-breathing (FB) IMPT and FB-helical tomotherapy, unless the target volumes were strictly localized anteriorly to the heart, but the presence of confounding factors (such as smoking, HTA, obesity, family history or chemotherapy) in the study population could have affected the conclusions of this study. Similarly, Rechner et al. [27] failed to demonstrate a benefit on cardiac mortality when IMPT (FB or DIBH) was compared with deep-inspiration breath-hold (DIBH)-IMRT. Scorsetti et al. [17] demonstrated a statistically significant reduction of cardiac mortality, IHD and HF with DIBH-IMPT compared with DIBH-VMAT; the absolute benefit on cardiac mortality was, however, limited $(0.16 \%$ for IMRT vs. $0.15 \%$ for proton therapy, $p=0.03$ ).

\subsection{Considerations on Other Organs-at-Risk}

HL RT is associated with an increased risk of radiation pneumonitis. Fox et al. [28] found that mean lung dose greater than 13.5 Gy and lung V20Gy > 33.5\% were predictive of radiation-induced pneumonitis for HL RT; the risk was increased in pre-transplant situations. Lyman-Kutcher-Burman (LKB) NTCP models for radiation pneumonitis were derived from a thymoma cohort by Moiseenko et al. [29] and from breast, lymphoma, and non-small cell lung cancer (NSCLC) cohorts by Seppenwoolde et al. [30]. Based on these models, Scorsetti et al. [17] estimated that DIBH-IMPT could significantly decrease radiation-induced pneumonitis (either symptomatic or radiographic) compared with DIBHVMAT. This benefit, while statistically significant, was clinically limited (EAR reduction between $0.09 \%$ and $1.09 \%$ ). In practice, with optimized multi-arc VMAT techniques, it 
is very uncommon to observe V20 above $30 \%$ or mean lung dose above 13.5 Gy, and, consequently, radiation pneumonitis is not seen any longer in daily practice with modern techniques. The potential benefit of proton therapy with regards to radiation-induced lung toxicity might thus be clinically inexistant in the modern era.

NTCP models were proposed for radiation-induced esophagitis. Chapet et al. [31] developed an LKB model based on a cohort of NSCLC patients treated with photon RT. Based on this model, Scorsetti et al. [17] found that proton therapy could reduce radiationinduced esophagitis probability from $2.61 \%$ with VMAT to $2.47 \%$ with proton therapy. More recently, Wang et al. [32] proposed an NTCP model based on a cohort of 328 NSCLC patients treated with proton therapy; to this date, this model has not been used in HL dosimetric studies.

Finally, an NTCP model has been developed by Palma et al. [33] for severe radiation dermatitis based on IMRT and IMPT on NSCLC cohort. Cutaneous toxicity has not been evaluated specifically for HL proton therapy, but Fellin et al. [34] found that breast proton therapy could increase skin morbidity compared with IMRT if the skin were not considered as an OAR. Delivered doses for HL lymphoma are usually lower than those for breast RT and skin toxicity for HL irradiation is usually not seen in daily practice with optimized IMRT; nevertheless, dosimetric studies could be useful to evaluate this potential issue in the context of HL irradiation with proton beams.

\section{Current Evidence for Hodgkin Lymphoma Proton Therapy}

\subsection{Clinical Tolerance and Efficacy Data}

To this date, published HL proton therapy trials are single-armed; whether the theoretical benefit of particle therapy in terms of late toxicity would be found in practice is still an open question. Available clinical data from published HL proton therapy studies are provided in Table 1.

Hoppe et al. [35] reported the first outcomes on a phase II trial including $15 \mathrm{HL}$ patients treated with involved node proton therapy in a consolidative setting. Doses ranged between $15 \mathrm{~Gy}$ and 39.6 Gy. With a median follow of 37 months, the 3-year relapsefree survival (RFS) and event-free survival (EFS) were respectively $93 \%$ and $87 \%$. No grade 3-4 toxicity was observed. A subsequent report on a larger cohort of 138 patients with a median follow-up of 32 months [36] confirmed the efficacy of HL proton therapy, with a 3-year RFS of 92\%, and its excellent tolerance profile, without grade 3-4 treatment-related toxicity. Similarly, no grade 3-4 pulmonary toxicity was observed by Nanda et al. [37] on $50 \mathrm{HL}$ patients (in a cohort of 59 lymphoma patients); while three early pulmonary grade 2 adverse events were described in this study, there were no $\geq$ grade 2 late toxicity. Ntentas et al. [38] did not observe any grade 3-4 toxicity on a cohort of 21 patients treated with involved site proton therapy, with a median follow-up of 24 months. Finally, the tolerance profile of proton therapy in the case of relapse/refractory ( $r / r)$ HL has also been evaluated by Tseng et al. [39] on a cohort of $85 \mathrm{r} / \mathrm{r}$ lymphoma patients (including $56 \mathrm{HL}$ patients) treated to a median dose of $36 \mathrm{~Gy}$. With a median follow-up of 26.3 months, no grade 3-4 pulmonary toxicity was observed; grade 2 pneumonitis ( $12.8 \%$ of the patients) could be predicted based on mean lung dose (MLD), lung V5Gy and V20Gy. All these trials compared favorably with IMRT, for which $4.5 \%$ of grade 3 toxicities have been reported in the consolidative setting and $12.5 \%$ for $\mathrm{r} / \mathrm{r}$ HL [40].

In addition, late asymptomatic cardiac and pulmonary toxicities have been specifically scrutinized using paraclinical exams by two studies. Bates et al. [41] followed five patients with magnetic resonance imaging (MRI), echocardiography and BNP dosage. With a median follow-up of 5 years, no changes were observed on MRI; however, the use of anthracycline-based regimen was associated with a mild asymptomatic left ventricle ejection fraction (LVEF) decline. O'steen et al. [42] measured the forced vital capacity and the forced expiratory volume in one second on 15 patients at one-year follow-up and did not find any significant change. Indeed, the follow-up is still too limited to conclude to a potential benefit on late cardiac or pulmonary toxicity or a reduction of second cancer inci- 
dence, but it appears to this point that HL proton therapy is well tolerated when indirectly compared to historical photon RT data.

Table 1. Published clinical data (2014-2021) on radiation exposure to organs-at-risk for Hodgkin lymphoma (HL) patients treated with proton therapy. Nanda et al. [37] and Tseng et al. [39] included non-Hodgkin lymphoma (NHL) patients in their studies. Pts.: patients. r/r: relapse refractory. RFS: relapse-free survival. EFS: event-free survival. OS: overall survival. LVEF: left ventricle ejection fraction. DLCO: diffusing capacity of lung for carbon monoxide.

\begin{tabular}{|c|c|c|c|c|c|c|}
\hline Study & Size & Situation & Dose (Gy) & Follow-Up & Efficacy & Tolerance \\
\hline $\begin{array}{l}\text { Hoppe } \\
\text { (2014) [35] }\end{array}$ & 15 pts. & First line & $\begin{array}{l}\text { 15-25.5 (children) } \\
\text { 30.6-39.6 (adults) }\end{array}$ & $\begin{array}{l}37 \text { months } \\
(26-55)\end{array}$ & $\begin{array}{l}\text { 3-year RFS: 93\% } \\
\text { 3-year EFS: } 87 \%\end{array}$ & No grade 3-4 toxicity (acute or late) \\
\hline $\begin{array}{l}\text { Hoppe } \\
(2017)[36]\end{array}$ & 138 pts. & First line & $\begin{array}{c}21(15-36) \\
\text { (children). } \\
30.6(20-45) \text { (adults) }\end{array}$ & 32 months (5-92) & $\begin{array}{l}\text { 3-year RFS: } 92 \% \\
\text { (96\% for adults; } \\
\text { 87\% for children). }\end{array}$ & No grade 3-4 toxicity (acute or late) \\
\hline $\begin{array}{l}\text { Nanda } \\
(2017)[37]\end{array}$ & $\begin{array}{c}50 \text { pts. } \\
\text { (+9 NHL pts.) }\end{array}$ & $\begin{array}{l}\text { First line and } \\
\mathrm{r} / \mathrm{r} \text { disease }\end{array}$ & $30.6(15-45)$ & 24.1 months (6-82) & NA & $\begin{array}{c}\text { Acute grade } 2 \text { pulmonary toxicity: } \\
\text { cough (3 pts) } \pm \text { pneumonitis ( } 1 \mathrm{pt}) \\
\pm \text { dyspnea ( } 2 \text { pts). } \\
\text { No grade } 3-4 \text { toxicity (acute or late) }\end{array}$ \\
\hline $\begin{array}{l}\text { Ntentas } \\
(2019)[38]\end{array}$ & 21 pts. & First line & 30 & 24 months (13-38) & $\begin{array}{l}\text { No recurrence. No } \\
\text { disease progression }\end{array}$ & No grade 3-4 toxicity (acute or late) \\
\hline $\begin{array}{c}\text { Tseng } \\
(2021)[39]\end{array}$ & $\begin{array}{c}56 \text { pts. } \\
(+29 \text { NHL pts.) }\end{array}$ & $\mathrm{r} / \mathrm{r}$ disease & $36(20-45)$ & $\begin{array}{l}25.6 \text { months } \\
(0.9-113.4)\end{array}$ & $\begin{array}{l}\text { 2-year PFS: } 73 \% . \\
\text { 2-year OS: } 91 \%\end{array}$ & $\begin{array}{l}12.8 \% \text { of grade } 2 \text { pneumonitis. } \\
\text { No grade } 3-4 \text { toxicity (acute or late) }\end{array}$ \\
\hline $\begin{array}{l}\text { Bates } \\
(2019)[41]\end{array}$ & 5 pts. & First line & $36(30.6-39.6)$ & 60 months & NA & $\begin{array}{l}\text { No grade } 3 \text { (acute or late). } \\
\text { No late cardiac symptomatology. } \\
\text { 5-year LVEF: } 60 \%(52 \%-61 \%) \text {. }\end{array}$ \\
\hline $\begin{array}{l}\text { O'steen } \\
(2019)[42]\end{array}$ & 15 pts. & First line & $30.6(21-39.6)$ & 12 months & NA & $\begin{array}{l}\text { 1-year DLCO: } 95.7 \% \text {. } \\
\text { 1-year Forced vital capacity: } 98.2 \% \text {. } \\
\text { 1-year mean forced expiratory } \\
\text { volume }(1 \mathrm{~s}): 97 \% .\end{array}$ \\
\hline
\end{tabular}

\subsection{Radiation Exposure to Organs-at-Risk}

Since no randomized controlled trials between proton therapy and IMRT have been conducted, dosimetric comparison studies between both techniques relied on a retrospective replanning of one of these two modalities. Such replanning is associated with an inherent risk of bias. Nevertheless, by pooling all available dosimetric HL comparison studies between proton therapy and photon RT, Tseng et al. [43] estimated that the average absolute dosimetric gain with proton therapy would be of 1.8 Gy for esophagus, 2.24 Gy for heart, 2.09 Gy for thyroid, 2.45 Gy for breast and 3.28 Gy for lungs. However, they highlighted the non-homogeneity of available studies, especially concerning the use of non-optimal photon planning and variability in volume definition. Whether this dosimetric gain "in silico" would finally translate into a clinical benefit for the patient in daily practice will be answered by long-term follow-up of HL proton therapy studies. Table 2.

Available dosimetric data from published HL proton therapy studies are provided in

Table 2. Published dosimetric data (2014-2021) on radiation exposure to organs-at-risk for Hodgkin lymphoma (HL) patients treated with proton therapy. Pts: patients. LAD: left anterior descending coronary artery. LV: left ventricle. RV: right ventricle. Nanda et al. [37] and Tseng et al. [39] included non-Hodgkin lymphoma (NHL) patients in their studies. Grey areas: dosimetric data not available.

\begin{tabular}{|c|c|c|c|c|c|c|c|c|c|}
\hline \multirow{2}{*}{ Study } & \multirow{2}{*}{ Size } & \multicolumn{8}{|c|}{ Average Mean Dose (Gy) } \\
\hline & & Heart & LAD & LV & RV & Lung & Breast & Thyroid & Esophagus \\
\hline Hoppe (2014) [35] & 15 pts. & 16.5 & & & & 11.6 & 6.3 & 19.3 & 20.3 \\
\hline Bates (2019) [41] & 5 pts. & 10.6 & 16.4 & 6.5 & 11.7 & & & & \\
\hline Ntentas (2019) [38] & 21 pts. & & & 2.0 & & 5.3 & 1.6 & 24.1 & 14.2 \\
\hline Nanda (2017) [37] & 50 pts. (+9 NHL pts.) & & & & & 7.2 & & & \\
\hline O'steen (2019) [42] & 15 pts. & & & & & 8.0 & & & \\
\hline Tseng (2021) [39] & 56 pts. (+29 NHL pts.) & 7.7 & & & & 7.3 & & & \\
\hline Pooled results & & 9.1 & & 2.9 & & 7.3 & 3.6 & 22.1 & 16.7 \\
\hline
\end{tabular}


On a cohort of 15 patients treated with involved node proton therapy, Hoppe et al. [35] reported an MHD of $8.9 \mathrm{~Gy}$, an MLD of 7.1 Gy, a mean dose to the breast of $4.3 \mathrm{~Gy}$, a mean dose to the thyroid of $15.8 \mathrm{~Gy}$ and a mean dose to the esophagus of $13.4 \mathrm{~Gy}$. Ntentas et al. [38] found somewhat lower doses to the OAR with an MHD of 7.7 Gy, an MLD of $5.3 \mathrm{~Gy}$, a mean dose to the left ventricle (LV) of 2.0 Gy, a mean dose to the breast of 1.6 Gy and a mean dose to the esophagus of 14.2 Gy. Nanda et al. [37] described an MLD of 7.2 Gy. Tseng et al. [39] reported an MHD of 7.7 Gy and an MLD of 7.3 Gy. Bates et al. [41] reported highly variable dosimetric values, ranging between 2.1 Gy and 19.7 Gy for MHD, between 2.9 Gy and 33.4 Gy for the left anterior descending coronary artery (LADCA), and between $0.5 \mathrm{~Gy}$ and $27.9 \mathrm{~Gy}$ for the LV.

It should be noted that the international lymphoma radiation oncology group (ILROG) mean dose recommendations [44] are less than 5 Gy for the heart, the left ventricle, and the other cardiac substructures, less than $4 \mathrm{~Gy}$ for the breasts and less than $10 \mathrm{~Gy}$ for the lungs. Consequently, while the MLD and the mean dose to the breasts observed in the available HL proton therapy studies were usually lower than the upper limits proposed by the ILROG guidelines, MHD was often higher than the recommended dose constraint.

\subsection{The Need for a Longer Follow-Up}

The clinical data for HL proton therapy consequently lack long-term follow-up and are relatively heterogeneous from a dosimetric point of view. In addition, proton therapy techniques continue to evolve; pencil beam scanning is gradually replacing passive scattering, and robust optimization methods and Monte-Carlo calculation algorithms are being currently generalized in treatment planning [45]. Yet, the development of NTCP models need long-term follow-up and robust dosimetric data. While acute pneumonitis risk for HL proton therapy might be extrapolated from $\mathrm{r} / \mathrm{r}$ HL proton therapy study by Tseng et al. [39], prediction of late toxicity risk could currently solely rely on photon NTCP models, which completely disregards specific radiobiological effect of proton beams [46] and relative biological effectiveness (RBE) variation issues $[47,48]$. There is consequently a need for larger population HL proton therapy studies to evaluate long-term adverse events and propose toxicity prediction models. The current registered ongoing study is the NCT03969693 trial, a prospective observational study with cardio-pulmonary monitoring which should include 50 patients. However, a larger population would probably be required to develop robust cardiac or pulmonary NTCP models.

\section{Randomized Controlled Trials for Hodgkin Lymphoma Proton Therapy: Challenges and Pitfalls}

\subsection{Epidemiological Considerations}

Randomized controlled trials (RCTs) are currently considered the gold standard in the era of evidenced-based medicine. However, contrasting with current RCT recruiting for breast cancer proton therapy [49], the development of an RCT for HL proton therapy is challenging since mediastinal HL is a rare malignancy. Townsend et al. [1] reported an incidence of 2.7-2.8 cases per 100,000 person-year, this corresponds approximately to 1700 new cases in the United Kingdom per year (compared to 50,000 breast cancers). According to Cancer Research UK [50], the proportion of limited-stage I-II HL lymphoma represents $55 \%$ of all cases; Filly et al. [51] estimated that $67 \%$ of all HL patients had a thoracic involvement. Therefore, for a country like the United Kingdom, it could be estimated that only 600 to $700 \mathrm{HL}$ patients per year have a localization amenable to proton therapy in a consolidative setting. Recruitment for a potential HL proton therapy RCT is consequently expected to be challenging.

\subsection{Defining Relevant Clinical Endpoints}

In addition, statistical hypotheses would be difficult to define a priori. On a cohort of 125 irradiated HL patients, Hahn et al. [52] observed 44 late cardiac adverse events, 70\% of which were ischemic; however, treatment was delivered using outdated 2D techniques. 
Leeuwen et al. [53] estimated that the cardiotoxicity risk increased after 5 to 35 years of follow-up and secondary cancer incidence after 5 to 15 years, remaining elevated for at least 40 years. Nevertheless, evaluating the potential cardiotoxicity risk reduction with proton therapy, based on the improved cardiac substructure sparing capacities of this technique, might be a clinically relevant endpoint [54].

On the other hand, the toxicity follow-up for HL VMAT, helical tomotherapy or IMRT is still limited, since these techniques are recent, and insufficient in any case to have a precise estimation of late radiation-induced toxicity with them; most of the clinical experience rely on limited size series [6]. In addition, it should be stressed the stochastic effect on carcinogenesis of low-dose bath is still unknown in practice [55] and the risk of second cancers with rotational IMRT is currently subject to intense debate [56]. The optimal population size and follow-up duration for a hypothetic HL proton therapy RCT would consequently be challenging to evaluate.

\subsection{The Ethical Aspects of RCTs for Proton Therapy}

The necessity of proton therapy RCT has been debated on an ethical point of view for a decade. Glatsein et al. [57] underlined the uncertainties about proton therapy efficacy and the importance of a measurable benefit (either enhanced anti-tumoral efficacy or toxicity reduction) to justify the financial cost of this technique; overall survival was proposed as a relevant endpoint for proton therapy RCT trials. Indeed, in a curable disease like HL, other endpoints would have to be considered, such as toxicity reduction.

On the other hand, Goitein et al. [58] considered that since proton therapy was associated with a better OAR sparing, there would be a high probability that it would be beneficial for the patient in almost all situations. There would consequently be an a priori unethical equipoise disequilibrium between the proton therapy and classic RT arms in such an RCT. This affirmation could be currently backed by a multiple tumor-site proton therapy RCT by Baumann et al. [59] which demonstrated that protons reduced acute adverse events with the same oncological outcome on a large population consisting of head and neck, pulmonary, cerebral, esophageal, gastric, rectal and pancreatic cancer patients. Bekelman et al. [60] underlined that insurance coverage inequalities (which is the case for proton therapy) may led to non-representativeness and hamper pace of enrollment of an RCT.

In any case, proton therapy is currently becoming cheaper and more accessible [61]; cost-effectiveness analyses might probably be less relevant to justify the implementation of this technique in the future. Nevertheless, to this date, identifying the best clinical indications is currently of prime importance due to the currently limited resources [56].

\subsection{Does Evidenced-Based HL Proton Therapy Need Randomized Trials?}

A potential HL proton therapy RCT would consequently face recruitment issues, statistical difficulties, and possible ethical debate. Barton et al. [62] argued that, when RCT would be considered unethical or unfeasible, high-quality observational studies might improve evidence level thanks to a larger size and greater representativeness of the study population. Large observational studies may be more sensitive to detect rare adverse events. Consequently, a convenient solution could be to develop national or international registries of HL patients treated with proton therapy and photon techniques to precisely evaluate outcomes and toxicities at a longer follow-up [63].

\section{Discussion}

Proton radiotherapy, taking advantage of proton beam physical properties, delivers targeted irradiation with minimal off-target dose scatter to adjacent tissues and OAR. It is consequently a promising approach for irradiation of HL patients who require RT. While RT was the first evaluated curative treatment of early-stage HL, the off-target radiation exposure resulted in potentially fatal RT-related toxicities, such as cardiovascular events 
or second primary malignancies that substantially increased with follow-up, particularly after 10 years [4].

In recent years, RT has been delivered to smaller fields, following chemotherapy, compared with total or subtotal nodal irradiation fields. Nevertheless, current practice of ISRT or INRT for localized HL usually consists of irradiation to all initially involved sites, regardless of the tumoral response to chemotherapy. Reduced radiation fields to residual sites only was evaluated in the HD15 study of the German Hodgkin Study Group for advanced HL [64]. Similarly, for early-stage HL, investigators at Memorial Sloan Kettering Cancer Center suggested that reduced fields might be sufficient for areas of remaining masses that were PET-positive following chemotherapy (residual site RT, RSRT), particularly in patients with bulky mediastinal disease: this concept was tested in newly diagnosed HL patients with bulky stage HL (IIA/BX) after four cycles of brentuximab vedotin, doxorubicin, vinblastine, and dacarbazine (BV-AVD) [65]. Most patients were PETor biopsy-negative after chemotherapy and were randomized to four cohorts: 25 patients to 30 Gy ISRT (cohort 1), 28 patients to 20 Gy ISRT (cohort 2), 29 patients to 30 Gy RSRT (cohort 3 ) and 24 patients to no further treatment (cohort 4). Complete response rates were 93-100\% among the four cohorts; 2-year progression-free survivals for cohorts 1 to 4 were $93 \%, 97 \%, 90 \%$ and $97 \%$, respectively. While this study was not powered to show efficacy differences, it suggested that achievement of complete response after completion of all treatments with reduced field RT or without RT could be predictive of a good short-term outcome. In the FITIL/FIL HD 0607 trial [66], patients with newly diagnosed stages IIX, III and IV HL were treated with two cycles of ABVD. Patients who were interim PET-negative received four additional cycles of ABVD while those who were interim PET-positive received escalated BEACOPP. Interim and end-of-treatment PET-negative patients were randomized to consolidation RT or no further treatment. At a 5-year median follow-up time, no difference in PFS or OS was observed. Consequently, interim and end-of-treatment PET negativity seems to identify a significant population of newly diagnosed HL patients who may not require consolidation RT.

Reducing the size of the treatment fields and minimizing off-target dose deposition represents a logical way to reduce radiation-induced toxicity. This can be achieved with modern photon beam techniques, such as rotational VMAT or helical tomotherapy, which reduce OAR exposure compared with 3D-RT [67] and increase treatment conformation [68]. In clinical practice, Besson et al. demonstrated that adoption of IMRT for HL irradiation reduced acute toxicities compared with 3D-RT ( $55 \%$ versus $71.4 \%$ for all grade toxicities, respectively) [6]. While proton therapy may further reduce OAR radiation exposure, whether or not this additional dosimetric benefit is clinically important enough to justify the expense of proton therapy is still an open question.

\section{Conclusions}

In conclusion, proton therapy for HL irradiation has the potential to reduce radiation exposure to several OARs, including cardiac substructures, which should significantly reduce late radiation-induced toxicities and secondary cancers. However, the clinical benefit of proton therapy is still uncertain and difficult to evaluate in practice, due to the limited follow-up, the presence of multiple confounding clinical variables, and the generalization of modern, highly conformal photon techniques such as DIBH-VMAT. While randomized controlled trials for HL proton therapy are probably unrealistic, the development of clinical registries might undoubtedly help to elucidate current uncertainties concerning this promising technique.

Author Contributions: Conceptualization: P.L., Y.K., E.O.; Methodology: P.L., Y.K., E.O. Writing: P.L. Review and Editing: P.L., L.D.M., R.D., A.M., A.I., V.V., A.B., A.R.F., B.A.J.-F., Y.K., E.O. Supervision: Y.K., E.O., Y.K. and E.O. contributed equally to the work. All authors have read and agreed to the published version of the manuscript.

Funding: This research received no external funding. 
Conflicts of Interest: The authors declare no conflict of interest.

$\begin{array}{ll}\text { Abbreviations } \\ \text { CT } & \text { Compute tomography } \\ \text { DIBH } & \text { Deep inspiration breath-hold } \\ \text { EAR } & \text { Excess absolute risk } \\ \text { FB } & \text { Free-breathing } \\ \text { HL } & \text { Hodgkin lymphoma } \\ \text { IMPT } & \text { Intensity modulated proton therapy } \\ \text { IMRT } & \text { Intensity modulated radiation therapy } \\ \text { INRT } & \text { Involved-node radiation therapy } \\ \text { ISRT } & \text { Involved-site radiation therapy } \\ \text { NTCP } & \text { Normal tissue complication probability } \\ \text { OAR } & \text { Organ-at-risk } \\ \text { RBE } & \text { Relative biological effectiveness } \\ \text { RR } & \text { Relative risk } \\ \text { RT } & \text { Radiation therapy } \\ \text { VMAT } & \text { Volumetric modulated arc therapy }\end{array}$

\section{References}

1. Townsend, W.; Linch, D. Hodgkin's Lymphoma in Adults. Lancet 2012, 380, 836-847. [CrossRef]

2. Cuccaro, A.; Bartolomei, F.; Cupelli, E.; Galli, E.; Giachelia, M.; Hohaus, S. Prognostic Factors in Hodgkin Lymphoma. Mediterr. J. Hematol. Infect. Dis. 2014, 6, e2014053. [CrossRef]

3. André, M.P.E.; Girinsky, T.; Federico, M.; Reman, O.; Fortpied, C.; Gotti, M.; Casasnovas, O.; Brice, P.; van der Maazen, R.; Re, A.; et al. Early Positron Emission Tomography Response-Adapted Treatment in Stage I and II Hodgkin Lymphoma: Final Results of the Randomized EORTC/LYSA/FIL H10 Trial. J. Clin. Oncol. 2017, 35, 1786-1794. [CrossRef]

4. Holtzman, A.L.; Stahl, J.M.; Zhu, S.; Morris, C.G.; Hoppe, B.S.; Kirwan, J.E.; Mendenhall, N.P. Does the Incidence of TreatmentRelated Toxicity Plateau After Radiation Therapy: The Long-Term Impact of Integral Dose in Hodgkin's Lymphoma Survivors. Adv. Radiat. Oncol. 2019, 4, 699-705. [CrossRef]

5. Wirth, A.; Mikhaeel, N.G.; Aleman, B.M.P.; Pinnix, C.C.; Constine, L.S.; Ricardi, U.; Illidge, T.M.; Eich, H.T.; Hoppe, B.S.; Dabaja, B.; et al. Involved Site Radiation Therapy in Adult Lymphomas: An Overview of International Lymphoma Radiation Oncology Group Guidelines. Int. J. Radiat. Oncol. Biol. Phys. 2020, 107, 909-933. [CrossRef] [PubMed]

6. Besson, N.; Pernin, V.; Zefkili, S.; Kirova, Y.M. Evolution of Radiation Techniques in the Treatment of Mediastinal Lymphoma: From 3D Conformal Radiotherapy (3DCRT) to Intensity-Modulated RT (IMRT) Using Helical Tomotherapy (HT): A Single-Centre Experience and Review of the Literature. Br. J. Radiol. 2016, 89, 20150409. [CrossRef] [PubMed]

7. Hoppe, B.S.; Flampouri, S.; Su, Z.; Latif, N.; Dang, N.H.; Lynch, J.; Joyce, M.; Sandler, E.; Li, Z.; Mendenhall, N.P. Effective Dose Reduction to Cardiac Structures Using Protons Compared with 3DCRT and IMRT in Mediastinal Hodgkin Lymphoma. Int. J. Radiat. Oncol. Biol. Phys. 2012, 84, 449-455. [CrossRef]

8. Hall, E.J.; Wuu, C.-S. Radiation-Induced Second Cancers: The Impact of 3D-CRT and IMRT. Int. J. Radiat. Oncol. Biol. Phys. 2003, 56, 83-88. [CrossRef]

9. Filippi, A.R.; Vanoni, V.; Meduri, B.; Cozzi, L.; Scorsetti, M.; Ricardi, U.; Lohr, F. Intensity Modulated Radiation Therapy and Second Cancer Risk in Adults. Int. J. Radiat. Oncol. Biol. Phys. 2018, 100, 17-20. [CrossRef] [PubMed]

10. Schaapveld, M.; Aleman, B.M.P.; van Eggermond, A.M.; Janus, C.P.M.; Krol, A.D.G.; van der Maazen, R.W.M.; Roesink, J.; Raemaekers, J.M.M.; de Boer, J.P.; Zijlstra, J.M.; et al. Second Cancer Risk Up to 40 Years after Treatment for Hodgkin's Lymphoma. N. Engl. J. Med. 2015, 373, 2499-2511. [CrossRef] [PubMed]

11. Facoetti, A.; Barcellini, A.; Valvo, F.; Pullia, M. The Role of Particle Therapy in the Risk of Radio-Induced Second Tumors: A Review of the Literature. Anticancer Res. 2019, 39, 4613-4617. [CrossRef] [PubMed]

12. Schneider, U.; Sumila, M.; Robotka, J. Site-Specific Dose-Response Relationships for Cancer Induction from the Combined Japanese A-Bomb and Hodgkin Cohorts for Doses Relevant to Radiotherapy. Theor. Biol. Med. Model. 2011, 8, 27. [CrossRef]

13. Sachs, R.K.; Brenner, D.J. Solid Tumor Risks after High Doses of Ionizing Radiation. Proc. Natl. Acad. Sci. USA 2005, 102, 13040-13045. [CrossRef] [PubMed]

14. Cella, L.; Conson, M.; Pressello, M.C.; Molinelli, S.; Schneider, U.; Donato, V.; Orecchia, R.; Salvatore, M.; Pacelli, R. Hodgkin's Lymphoma Emerging Radiation Treatment Techniques: Trade-Offs between Late Radio-Induced Toxicities and Secondary Malignant Neoplasms. Radiat. Oncol. 2013, 8, 22. [CrossRef]

15. Voong, K.R.; McSpadden, K.; Pinnix, C.C.; Shihadeh, F.; Reed, V.; Salehpour, M.R.; Arzu, I.; Wang, H.; Hodgson, D.; Garcia J.; et al. Dosimetric Advantages of a "Butterfly" Technique for Intensity-Modulated Radiation Therapy for Young Female Patients with Mediastinal Hodgkin's Lymphoma. Radiat. Oncol. 2014, 9, 94. [CrossRef] 
16. König, L.; Haering, P.; Lang, C.; Splinter, M.; von Nettelbladt, B.; Weykamp, F.; Hoegen, P.; Lischalk, J.W.; Herfarth, K.; Debus, J.; et al. Secondary Malignancy Risk Following Proton vs. X-ray Treatment of Mediastinal Malignant Lymphoma: A Comparative Modeling Study of Thoracic Organ-Specific Cancer Risk. Front. Oncol. 2020, 10. [CrossRef] [PubMed]

17. Scorsetti, M.; Cozzi, L.; Navarria, P.; Fogliata, A.; Rossi, A.; Franceschini, D.; De Rose, F.; Franzese, C.; Carlo-Stella, C.; Santoro, A. Intensity Modulated Proton Therapy Compared to Volumetric Modulated Arc Therapy in the Irradiation of Young Female Patients with Hodgkin's Lymphoma. Assessment of Risk of Toxicity and Secondary Cancer Induction. Radiat. Oncol. 2020, 15, 12. [CrossRef]

18. Timlin, C.; Loken, J.; Kruse, J.; Miller, R.; Schneider, U. Comparing Second Cancer Risk for Multiple Radiotherapy Modalities in Survivors of Hodgkin Lymphoma. Br. J. Radiol. 2021, 94, 20200354. [CrossRef]

19. Filippi, A.R.; Meregalli, S.; DI Russo, A.; Levis, M.; Ciammella, P.; Buglione, M.; Guerini, A.E.; De Marco, G.; De Sanctis, V.; Vagge, S.; et al. Fondazione Italiana Linfomi (FIL) Expert Consensus on the Use of Intensity-Modulated and Image-Guided Radiotherapy for Hodgkin's Lymphoma Involving the Mediastinum. Radiat. Oncol. 2020, 15, 62. [CrossRef] [PubMed]

20. Filippi, A.R.; Ragona, R.; Piva, C.; Scafa, D.; Fiandra, C.; Fusella, M.; Giglioli, F.R.; Lohr, F.; Ricardi, U. Optimized Volumetric Modulated Arc Therapy versus 3D-CRT for Early Stage Mediastinal Hodgkin Lymphoma without Axillary Involvement: A Comparison of Second Cancers and Heart Disease Risk. Int. J. Radiat. Oncol. Biol. Phys. 2015, 92, 161-168. [CrossRef]

21. van Nimwegen, F.A.; Schaapveld, M.; Janus, C.P.M.; Krol, A.D.G.; Petersen, E.J.; Raemaekers, J.M.M.; Kok, W.E.M.; Aleman, B.M.P.; van Leeuwen, F.E. Cardiovascular Disease after Hodgkin Lymphoma Treatment: 40-Year Disease Risk. JAMA Intern. Med. 2015, 175, 1007-1017. [CrossRef]

22. Gagliardi, G.; Constine, L.S.; Moiseenko, V.; Correa, C.; Pierce, L.J.; Allen, A.M.; Marks, L.B. Radiation Dose-Volume Effects in the Heart. Int. J. Radiat. Oncol. Biol. Phys. 2010, 76, S77-S85. [CrossRef]

23. Cella, L.; Liuzzi, R.; Conson, M.; D'Avino, V.; Salvatore, M.; Pacelli, R. Multivariate Normal Tissue Complication Probability Modeling of Heart Valve Dysfunction in Hodgkin Lymphoma Survivors. Int. J. Radiat. Oncol. Biol. Phys. 2013, 87, 304-310. [CrossRef] [PubMed]

24. Hoppe, B.S.; Bates, J.E.; Mendenhall, N.P.; Morris, C.G.; Louis, D.; Ho, M.W.; Hoppe, R.T.; Shaikh, M.; Li, Z.; Flampouri, S. The Meaningless Meaning of Mean Heart Dose in Mediastinal Lymphoma in the Modern Radiation Therapy Era. Pract. Radiat. Oncol. 2019. [CrossRef]

25. Taparra, K.; Lester, S.C.; Harmsen, W.S.; Petersen, M.; Funk, R.K.; Blanchard, M.J.; Young, P.; Herrmann, J.; Hunzeker, A.; Schultz, H.; et al. Reducing Heart Dose with Protons and Cardiac Substructure Sparing for Mediastinal Lymphoma Treatment. Int. J. Part. Ther. 2020, 7, 1-12. [CrossRef] [PubMed]

26. Toltz, A.; Shin, N.; Mitrou, E.; Laude, C.; Freeman, C.R.; Seuntjens, J.; Parker, W.; Roberge, D. Late Radiation Toxicity in Hodgkin Lymphoma Patients: Proton Therapy's Potential. J. Appl. Clin. Med. Phys. 2015, 16, 167-178. [CrossRef] [PubMed]

27. Rechner, L.A.; Maraldo, M.V.; Vogelius, I.R.; Zhu, X.R.; Dabaja, B.S.; Brodin, N.P.; Petersen, P.M.; Specht, L.; Aznar, M.C. Life Years Lost Attributable to Late Effects after Radiotherapy for Early Stage Hodgkin Lymphoma: The Impact of Proton Therapy and/or Deep Inspiration Breath Hold. Radiother. Oncol. 2017, 125, 41-47. [CrossRef]

28. Fox, A.M.; Dosoretz, A.P.; Mauch, P.M.; Chen, Y.-H.; Fisher, D.C.; LaCasce, A.S.; Freedman, A.S.; Silver, B.; Ng, A.K. Predictive Factors for Radiation Pneumonitis in Hodgkin Lymphoma Patients Receiving Combined-Modality Therapy. Int. J. Radiat. Oncol. Biol. Phys. 2012, 83, 277-283. [CrossRef]

29. Moiseenko, V.; Craig, T.; Bezjak, A.; Van Dyk, J. Dose-Volume Analysis of Lung Complications in the Radiation Treatment of Malignant Thymoma: A Retrospective Review. Radiother. Oncol. 2003, 67, 265-274. [CrossRef]

30. Seppenwoolde, Y.; Lebesque, J.V.; de Jaeger, K.; Belderbos, J.S.A.; Boersma, L.J.; Schilstra, C.; Henning, G.T.; Hayman, J.A.; Martel, M.K.; Ten Haken, R.K. Comparing Different NTCP Models That Predict the Incidence of Radiation Pneumonitis. Normal Tissue Complication Probability. Int. J. Radiat. Oncol. Biol. Phys. 2003, 55, 724-735. [CrossRef]

31. Chapet, O.; Kong, F.-M.; Lee, J.S.; Hayman, J.A.; Ten Haken, R.K. Normal Tissue Complication Probability Modeling for Acute Esophagitis in Patients Treated with Conformal Radiation Therapy for Non-Small Cell Lung Cancer. Radiother. Oncol. 2005, 77, 176-181. [CrossRef] [PubMed]

32. Wang, Z.; Chen, M.; Sun, J.; Jiang, S.; Wang, L.; Wang, X.; Sahoo, N.; Gunn, G.B.; Frank, S.J.; Nguyen, Q.-N.; et al. Lyman-KutcherBurman Normal Tissue Complication Probability Modeling for Radiation-Induced Esophagitis in Non-Small Cell Lung Cancer Patients Receiving Proton Radiotherapy. Radiother. Oncol. 2020, 146, 200-204. [CrossRef]

33. Palma, G.; Monti, S.; Conson, M.; Xu, T.; Hahn, S.; Durante, M.; Mohan, R.; Liao, Z.; Cella, L. NTCP Models for Severe Radiation Induced Dermatitis After IMRT or Proton Therapy for Thoracic Cancer Patients. Front. Oncol. 2020, 10, 344. [CrossRef] [PubMed]

34. Fellin, F.; Iacco, M.; D’Avino, V.; Tommasino, F.; Farace, P.; Palma, G.; Conson, M.; Giacomelli, I.; Zucchetti, C.; Falcinelli, L.; et al. Potential Skin Morbidity Reduction with Intensity-Modulated Proton Therapy for Breast Cancer with Nodal Involvement. Acta Oncol. 2019, 58, 934-942. [CrossRef] [PubMed]

35. Hoppe, B.S.; Flampouri, S.; Zaiden, R.; Slayton, W.; Sandler, E.; Ozdemir, S.; Dang, N.H.; Lynch, J.W.; Li, Z.; Morris, C.G.; et al. Involved-Node Proton Therapy in Combined Modality Therapy for Hodgkin Lymphoma: Results of a Phase 2 Study. Int. J. Radiat. Oncol. Biol. Phys. 2014, 89, 1053-1059. [CrossRef] [PubMed]

36. Hoppe, B.S.; Hill-Kayser, C.E.; Tseng, Y.D.; Flampouri, S.; Elmongy, H.M.; Cahlon, O.; Mendenhall, N.P.; Maity, A.; McGee, L.A.; Plastaras, J.P. Consolidative Proton Therapy after Chemotherapy for Patients with Hodgkin Lymphoma. Ann. Oncol. 2017, 28, 2179-2184. [CrossRef] 
37. Nanda, R.; Flampouri, S.; Mendenhall, N.P.; Indelicato, D.J.; Jones, L.M.; Seeram, V.K.; Hoppe, B.S. Pulmonary Toxicity Following Proton Therapy for Thoracic Lymphoma. Int. J. Radiat. Oncol. Biol. Phys. 2017, 99, 494-497. [CrossRef]

38. Ntentas, G.; Dedeckova, K.; Andrlik, M.; Aznar, M.C.; George, B.; Kubeš, J.; Darby, S.C.; Cutter, D.J. Clinical Intensity Modulated Proton Therapy for Hodgkin Lymphoma: Which Patients Benefit the Most? Pract. Radiat. Oncol. 2019, 9, 179-187. [CrossRef] [PubMed]

39. Tseng, Y.D.; Hoppe, B.S.; Dedeckova, K.; Patel, C.G.; Hill-Kayser, C.E.; Miller, D.M.; Maity, A.; Mendenhall, N.P.; Mailhot Vega, R.B.; Yock, T.I.; et al. Risk of Pneumonitis and Outcomes After Mediastinal Proton Therapy for Relapsed/Refractory Lymphoma: A PTCOG and PCG Collaboration. Int. J. Radiat. Oncol. Biol. Phys. 2021, 109, 220-230. [CrossRef]

40. Pinnix, C.C.; Smith, G.L.; Milgrom, S.; Osborne, E.M.; Reddy, J.P.; Akhtari, M.; Reed, V.; Arzu, I.; Allen, P.K.; Wogan, C.F.; et al. Predictors of Radiation Pneumonitis in Patients Receiving Intensity Modulated Radiation Therapy for Hodgkin and Non-Hodgkin Lymphoma. Int. J. Radiat. Oncol. Biol. Phys. 2015, 92, 175-182. [CrossRef]

41. Bates, J.E.; Klassen, C.; Ozdemir, S.; Flampouri, S.; Percy, R.; Mendenhall, N.P.; Hoppe, B.S. Cardiac MRI for Detecting Early Cardiac Toxicity after Proton Therapy for Hodgkin Lymphoma. Int. J. Part. Ther. 2019, 5, 41-44. [CrossRef]

42. O'steen, L.; Bellardini, J.; Cury, J.; Jones, L.; Seeram, V.K.; Mendenhall, N.P.; Hoppe, B.S. Pulmonary Function after Proton Therapy for Hodgkin Lymphoma. Int. J. Part. Ther. 2019, 5, 1-4. [CrossRef] [PubMed]

43. Tseng, Y.D.; Cutter, D.J.; Plastaras, J.P.; Parikh, R.R.; Cahlon, O.; Chuong, M.D.; Dedeckova, K.; Khan, M.K.; Lin, S.-Y.; McGee, L.A.; et al. Evidence-Based Review on the Use of Proton Therapy in Lymphoma From the Particle Therapy Cooperative Group (PTCOG) Lymphoma Subcommittee. Int. J. Radiat. Oncol. Biol. Phys. 2017, 99, 825-842. [CrossRef] [PubMed]

44. Dabaja, B.S.; Hoppe, B.S.; Plastaras, J.P.; Newhauser, W.; Rosolova, K.; Flampouri, S.; Mohan, R.; Mikhaeel, N.G.; Kirova, Y.; Specht, L.; et al. Proton Therapy for Adults with Mediastinal Lymphomas: The International Lymphoma Radiation Oncology Group Guidelines. Blood 2018, 132, 1635-1646. [CrossRef] [PubMed]

45. Schuemann, J.; Giantsoudi, D.; Grassberger, C.; Moteabbed, M.; Min, C.H.; Paganetti, H. Assessing the Clinical Impact of Approximations in Analytical Dose Calculations for Proton Therapy. Int. J. Radiat. Oncol. Biol. Phys. 2015, 92, 1157-1164. [CrossRef] [PubMed]

46. Vitti, E.T.; Parsons, J.L. The Radiobiological Effects of Proton Beam Therapy: Impact on DNA Damage and Repair. Cancers 2019, 11, 946. [CrossRef] [PubMed]

47. Paganetti, H.; Giantsoudi, D. Relative Biological Effectiveness Uncertainties and Implications for Beam Arrangements and Dose Constraints in Proton Therapy. Semin. Radiat. Oncol. 2018, 28, 256-263. [CrossRef] [PubMed]

48. Ilicic, K.; Combs, S.E.; Schmid, T.E. New Insights in the Relative Radiobiological Effectiveness of Proton Irradiation. Radiat. Oncol. 2018, 13, 6. [CrossRef]

49. Bekelman, J.E.; Lu, H.; Pugh, S.; Baker, K.; Berg, C.D.; de Gonzalez, A.B.; Braunstein, L.Z.; Bosch, W.; Chauhan, C.; Ellenberg, S.; et al. Pragmatic Randomised Clinical Trial of Proton versus Photon Therapy for Patients with Non-Metastatic Breast Cancer: The Radiotherapy Comparative Effectiveness (RadComp) Consortium Trial Protocol. BMJ Open 2019, 9, e025556. [CrossRef]

50. Cancer Research UK. Hodgkin Lymphoma. Available online: https://www.cancerresearchuk.org/about-cancer/hodgkinlymphoma (accessed on 18 June 2021).

51. Filly, R.; Bland, N.; Castellino, R.A. Radiographic Distribution of Intrathoracic Disease in Previously Untreated Patients with Hodgkin's Disease and Non-Hodgkin's Lymphoma. Radiology 1976, 120, 277-281. [CrossRef] [PubMed]

52. Hahn, E.; Jiang, H.; Ng, A.; Bashir, S.; Ahmed, S.; Tsang, R.; Sun, A.; Gospodarowicz, M.; Hodgson, D. Late Cardiac Toxicity After Mediastinal Radiation Therapy for Hodgkin Lymphoma: Contributions of Coronary Artery and Whole Heart Dose-Volume Variables to Risk Prediction. Int. J. Radiat. Oncol. Biol. Phys. 2017, 98, 1116-1123. [CrossRef]

53. van Leeuwen, F.E.; Ng, A.K. Long-Term Risk of Second Malignancy and Cardiovascular Disease after Hodgkin Lymphoma Treatment. Hematol. Am. Soc. Hematol. Educ. Program 2016, 2016, 323-330. [CrossRef]

54. Levis, M.; Filippi, A.R.; Fiandra, C.; De Luca, V.; Bartoncini, S.; Vella, D.; Ragona, R.; Ricardi, U. Inclusion of Heart Substructures in the Optimization Process of Volumetric Modulated Arc Therapy Techniques May Reduce the Risk of Heart Disease in Hodgkin's Lymphoma Patients. Radiother. Oncol. 2019, 138, 52-58. [CrossRef]

55. Little, M.P.; Wakeford, R.; Tawn, E.J.; Bouffler, S.D.; Berrington de Gonzalez, A. Risks Associated with Low Doses and Low Dose Rates of Ionizing Radiation: Why Linearity May Be (Almost) the Best We Can Do. Radiology 2009, 251, 6-12. [CrossRef] [PubMed]

56. Alongi, F.; Giaj-Levra, N.; Fiorentino, A.; Mazzola, R.; Fersino, S.; Ricchetti, F.; Ruggieri, R. Low-Dose Bath with Volumetric Modulated Arc Therapy in Breast Cancer: "Much Ado about Nothing?". Tumori 2016, 102, 335-336. [CrossRef]

57. Glatstein, E.; Glick, J.; Kaiser, L.; Hahn, S.M. Should Randomized Clinical Trials Be Required for Proton Radiotherapy? An Alternative View. J. Clin. Oncol. 2008, 26, 2438-2439. [CrossRef]

58. Goitein, M.; Cox, J.D. Should Randomized Clinical Trials Be Required for Proton Radiotherapy? J. Clin. Oncol. 2008, 26, 175-176. [CrossRef] [PubMed]

59. Baumann, B.C.; Mitra, N.; Harton, J.G.; Xiao, Y.; Wojcieszynski, A.P.; Gabriel, P.E.; Zhong, H.; Geng, H.; Doucette, A.; Wei, J.; et al. Comparative Effectiveness of Proton vs Photon Therapy as Part of Concurrent Chemoradiotherapy for Locally Advanced Cancer. JAMA Oncol. 2020, 6, 237-246. [CrossRef] [PubMed]

60. Bekelman, J.E.; Denicoff, A.; Buchsbaum, J. Randomized Trials of Proton Therapy: Why They Are at Risk, Proposed Solutions, and Implications for Evaluating Advanced Technologies to Diagnose and Treat Cancer. J. Clin. Oncol. 2018, 36, 2461-2464. [CrossRef] 
61. Schippers, J.M.; Lomax, A.; Garonna, A.; Parodi, K. Can Technological Improvements Reduce the Cost of Proton Radiation Therapy? Semin. Radiat. Oncol. 2018, 28, 150-159. [CrossRef] [PubMed]

62. Barton, S. Which Clinical Studies Provide the Best Evidence? The Best RCT Still Trumps the Best Observational Study. BMJ 2000, 321, 255-256. [CrossRef]

63. Loap, P.; Goudjil, F.; Dendale, R.; Kirova, Y. Clinical and Technical Considerations for Mediastinal Hodgkin Lymphoma Protontherapy Based on a Single-Center Early Experience. Cancer Radiother. 2021, S1278-S3218. [CrossRef]

64. Engert, A.; Haverkamp, H.; Kobe, C.; Markova, J.; Renner, C.; Ho, A.; Zijlstra, J.; Král, Z.; Fuchs, M.; Hallek, M.; et al. ReducedIntensity Chemotherapy and PET-Guided Radiotherapy in Patients with Advanced Stage Hodgkin's Lymphoma (HD15 Trial): A Randomised, Open-Label, Phase 3 Non-Inferiority Trial. Lancet 2012, 379, 1791-1799. [CrossRef]

65. Kumar, A.; Casulo, C.; Advani, R.H.; Budde, E.; Barr, P.M.; Batlevi, C.L.; Caron, P.; Constine, L.S.; Dandapani, S.V.; Drill, E.; et al. Brentuximab Vedotin Combined with Chemotherapy in Patients With Newly Diagnosed Early-Stage, Unfavorable-Risk Hodgkin Lymphoma. J. Clin. Oncol. 2021, 39. [CrossRef] [PubMed]

66. Gallamini, A.; Rossi, A.; Patti, C.; Picardi, M.; Romano, A.; Cantonetti, M.; Oppi, S.; Viviani, S.; Bolis, S.; Trentin, L.; et al. Consolidation Radiotherapy Could Be Safely Omitted in Advanced Hodgkin Lymphoma with Large Nodal Mass in Complete Metabolic Response After ABVD: Final Analysis of the Randomized GITIL/FIL HD0607 Trial. J. Clin. Oncol. 2020, 38, 3905-3913. [CrossRef]

67. Kirova, Y.M.; Chargari, C. Applications of New Irradiation Modalities in Patients with Lymphoma: Promises and Uncertainties. World J. Radiol. 2011, 3, 66-69. [CrossRef] [PubMed]

68. Fiandra, C.; Filippi, A.R.; Catuzzo, P.; Botticella, A.; Ciammella, P.; Franco, P.; Borca, V.C.; Ragona, R.; Tofani, S.; Ricardi, U. Different IMRT Solutions vs. 3D-Conformal Radiotherapy in Early Stage Hodgkin's Lymphoma: Dosimetric Comparison and Clinical Considerations. Radiat. Oncol. 2012, 7, 186. [CrossRef] [PubMed] 